\title{
Genome-wide association study of blast resistance in indica rice
}

\author{
Caihong Wang ${ }^{1}$, Yaolong Yang ${ }^{1,2}$, Xiaoping Yuan' ${ }^{1}$ Qun Xu', Yue Feng ${ }^{1}$, Hanyong Yu' , Yiping Wang ${ }^{1}$ \\ and Xinghua Wei ${ }^{1^{*}}$
}

\begin{abstract}
Background: Rice blast disease is one of the most serious and recurrent problems in rice-growing regions worldwide. Most resistance genes were identified by linkage mapping using genetic populations. We extensively examined 16 rice blast strains and a further genome-wide association study based on genotyping 0.8 million single nucleotide polymorphism variants across 366 diverse indica accessions.

Results: Totally, thirty associated loci were identified. The strongest signal (Chr11_6526998, $P=1.17 \times 10^{-17}$ ) was located within the gene Os1190225100, one of the rice Pia-blast resistance gene. Another association signal (Chr11_30606558) was detected around the QTL Pif. Our study identified the gene Os1190704100, a disease resistance protein containing nucleotide binding site-leucine rich repeat domain, as the main candidate gene of Pif. In order to explore the potential mechanism underlying the blast resistance, we further examined a locus in chromosome 12, which was associated with $\mathrm{CH} 149\left(P=7.53 \times 10^{-15}\right)$. The genes, Os 1290424700 and Os 12g0427000, both described as kinase-like domain containing protein, were presumed to be required for the full function of this locus. Furthermore, we found some association on chromosome 3, in which it has not been reported any loci associated with rice blast resistance. In addition, we identified novel functional candidate genes, which might participate in the resistance regulation.
\end{abstract}

Conclusions: This work provides the basis of further study of the potential function of these candidate genes. A subset of true associations would be weakly associated with outcome in any given GWAS; therefore, large-scale replication is necessary to confirm our results. Future research will focus on validating the effects of these candidate genes and their functional variants using genetic transformation and transferred DNA insertion mutant screens, to verify that these genes engender resistance to blast disease in rice.

Keywords: Blast disease, Candidate gene, Genome-wide association study, Oryza sativa L, R protein

\section{Background}

Rice blast disease is a serious and recurrent problem in all rice-growing regions of the world. It is estimated that every year the rice destroyed by the disease could feed 60 million people [1]. The disease is caused by the fungus Magnaporthe oryzae, which is the teleomorph of a complex genus of Ascomycete fungi composed of interfertile anamorphs $[2,3]$. The fungus is highly adaptive to its host and is capable of causing infection at any growing stage. The diversity of the pathogen and the complexity of the

\footnotetext{
*Correspondence: weixinghua@caas.cn

'State Key Laboratory of Rice Biology, China National Rice Research Institute, Hangzhou 310006, China

Full list of author information is available at the end of the article
}

disease make it to be a formidable challenge for fully solving the problem [1].

The use of resistance $(R)$ genes in crop breeding programs has been, and will undoubtedly remain the major means for disease control. In rice, about $180 R$ genes have been isolated to the disease caused by a pathogen infection (http://www.ricedata.cn/ontology). Based on the conserved motifs (nucleotide-binding site (NBS), leucine-rich repeat (LRR), toll-interleukin receptor (TIR), coiled-coil (CC), transmembrance receptor (TM), protein kinase (PK)), $R$ genes were classified into four kinds, referring to NBS-LRR, RLK, LRR-TM, TM-CC [4]. More than 68 loci, involved in rice blast resistance, referring to 83 major blast resistance genes, have been identified, and at least 24 resistance genes have been cloned (http://www.ricedata.cn/gene). Blast 
resistance is generally classified into complete and partial resistance [5]. Complete resistance to blast, controlled by a major gene, is qualitative and race specific, involving genes such as Pib [6], Pita [7], and Pi9 [8]. Partial resistance to blast, on other hand, is considered to be quantitative and durable because of its generally non-race-specific and polygenic characteristics. Many partial resistant locus have been identified, such as pi-21 $[9,10]$. A rice plant cannot be resistant to an isolate of Magnaporthe oryzae unless the pathogen has the genes that make it avirulent on that rice plant. An isolate of Magnaporthe oryzae cannot be avirulent on a rice plant unless the rice plant has genes that make it resistant to that isolate [11]. Hence, cultivating rice varieties with highly efficient, durable resistance to blast is still the most economically feasible and environmentally sound management approach in most blast-prone rice ecosystems.

The QTL approach, specific to the genetic population, is not suitable to identify the tremendous phenotypic variation within the scope of the whole genome [12,13]. The genome-wide association study (GWAS) has emerged as a powerful approach for simultaneously screening genetic variation underlying complex phenotype. In 2005, GWAS was first applied to a human disease, age-related macular degeneration [14]. Subsequently, a series of GWAS research have been published [15-18]. However, GWAS applied to the dissection of complex traits in animals and plants are only just beginning because of the lack of effective genotyping techniques and the limited resources for developing high-density haplotype maps. For both QTL approach and GWAS, genetic transformation is generally required to identify the candidate gene(s).

In rice, increasing amounts of genomic resources have been created in terms of genome sequences [19,20] and high-density SNP maps [12,21,22]. Huang et al.[21,22] used Illumina next-generation sequencing of abundant rice landraces worldwide to generate low-coverage sequence data across the lines and construct a comprehensive HapMap for rice (Oryza sativa) that could be used for GWAS for agronomic traits. In our study, we extensively examined blast resistance in a genome-wide association study (GWAS) based on genotyping 805,158 SNPs variants across 366 indica diverse accessions [21,22]. The goal of this study was, using GWAS, to identify a substantial number of loci related to blast resistance that could be important for rice production and improvement.

\section{Results}

\section{Phenotypic variation}

We investigated the concentrations of 16 strains of rice blast on seedlings, and evaluated resistance to rice blast by DLA on each experimental plot. The correlation coefficient indicated that DLA by blast strains $\mathrm{CH} 131, \mathrm{CH} 154$ and $\mathrm{CH} 159$ was significantly associated with latitude (respectively $r=0.12, P=2.4 \times 10^{-2} ; r=0.15, P=3.4 \times 10^{-3}$; $r=0.14, P=6.9 \times 10^{-3}$ ) while DLA by $\mathrm{CH} 251$ was associated with longitude $\left(r=-0.27, P=1.6 \times 10^{-7}\right)$ (Additional file 1: Figure S1). Based on the SharedAllele distance [23] using the unweighted pair-group method with arithmetic mean (UPGMA) [24], the set of strains could be divided into two groups: one group only consisted of the strains $\mathrm{CH} 131, \mathrm{CH} 212, \mathrm{CH} 362$ and $\mathrm{CH} 193$, which have the weaker pathogenicity, and the other comprised the remaining 12 strains, which have the stronger pathogenicity (Additional file 2: Figure S2).

\section{GWAS for resistance to 16 blast strains}

To investigate the genotypic variation underlying resistance to rice blast, GWAS was carried out to identify the associated loci in indica rice landraces, using the EMMAX algorithm [25]. We identified a total of 30 associated loci using $P=1.0 \times 10^{-8}$ as the genome-wide significance thresholds (Figure 1, Table 1). $50 \%$ of the detected strains (8 out of 16) had at least one significant association, with an average of 3.8 associations per strains. The $\mathrm{CH} 171$ strain had most with eight associations, followed by $\mathrm{CH} 182$ with seven, while $\mathrm{CH} 186, \mathrm{CH} 212$ and $\mathrm{CH} 362$ only had one. Genome-wide analysis of the associated loci existed random distribution across the 12 chromosomes. Of these loci, most seven were separately distributed on chromosome 11 and chromosome 12, while none were on chromosome 10. The chromosome distributions of the associated loci are presented in Additional file 3: Figure S3, possessing similar trends with the distributions of the known loci. Furthermore, GWAS hot spots were located on chromosome 11 and 12, which was consistent with the reported research [26]. And the same/nearby SNPs were significantly associated with multiple traits. For example, SNPs at $30.6 \mathrm{Mb}$ on chromosome 11 were associated with $\mathrm{CH} 182$ and $\mathrm{CH} 149$, SNPs at $13.0 \mathrm{Mb}$ on chromosome 12 with $\mathrm{CH} 172$ and $\mathrm{CH} 186$. This illustrated that these strains might have common mechanisms and be caused by pleiotropic or closely linked genes. The significant loci detected are also illustrated, corresponding to disease resistance protein, NBSLRR protein, kinase-like domain containing protein, heavy metal transport/detoxification protein and other known and unknown proteins (Additional file 4: Figure S4).

\section{Assessment of GWAS findings and function identification of candidate genes}

Searching the flanking regions of the associated loci, four were located close to or even landed on two known cloned genes (Pia [27], Pik [28]), and one QTL (Pif [29]), identified previously using near isogenic lines or recombinant inbred lines with map-based cloning, which illustrated the relatively high resolution of our GWAS. We forecasted candidate genes through searching a protein that contained the conserved motifs of $R$ gene. To further verify the 


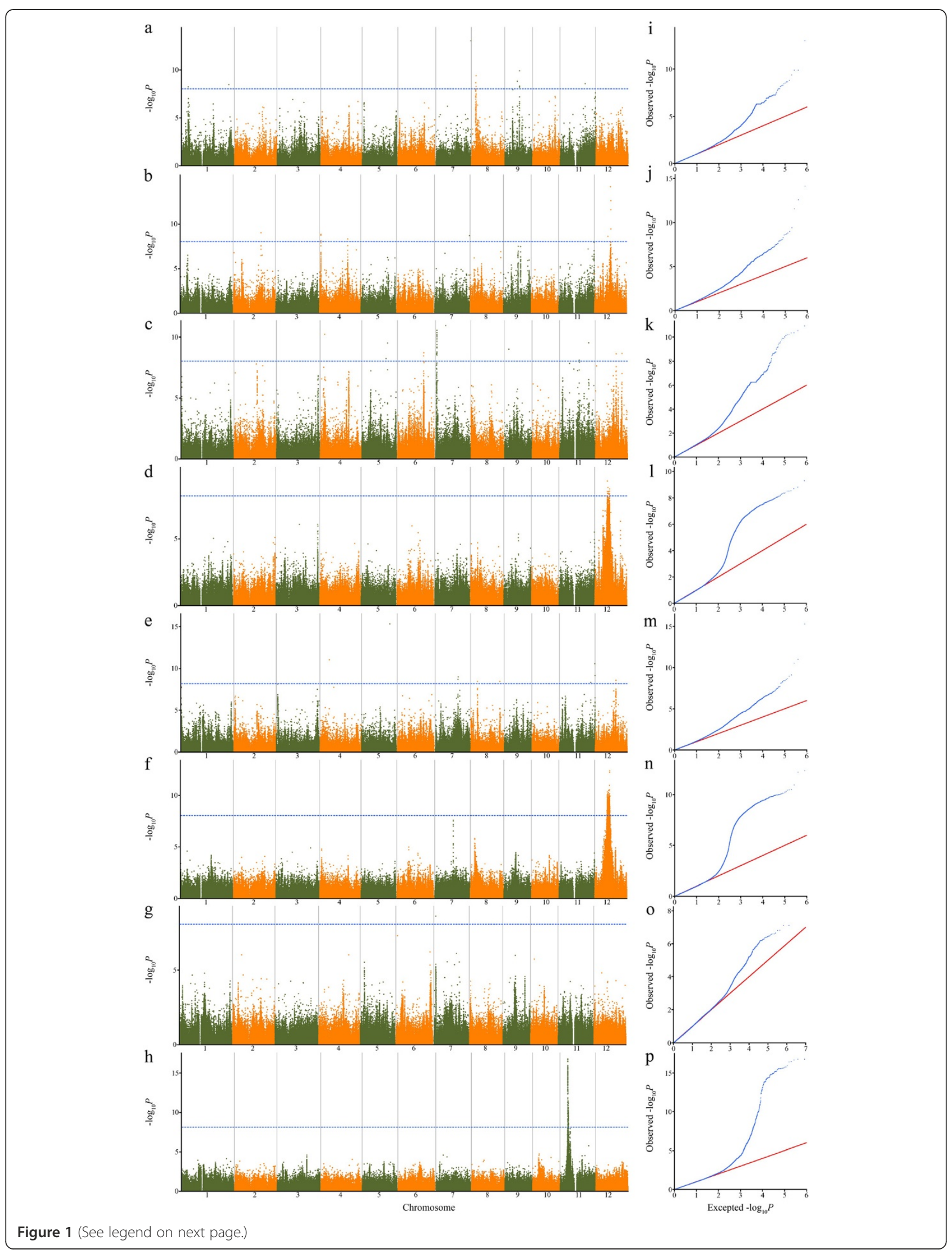


(See figure on previous page.)

Figure 1 Genome-wide association studies of rice blast resistance. Manhattan plots for eight strains, (a) $\mathrm{CH} 102$, (b) $\mathrm{CH} 149$, (c) $\mathrm{CH} 171$, (d) $\mathrm{CH} 172$, (e) $\mathrm{CH} 182$, (f) $\mathrm{CH} 186$, (g) $\mathrm{CH} 212$, (h) $\mathrm{CH} 362$. Negative log10-transformed $P$ values from a genome-wide scan are plotted against position on each of 12 chromosomes. Gray horizontal dashed line indicates the genome-wide significance threshold. Quantitle-quantitle plot for the eight strains, (i) $\mathrm{CH} 102$, (j) $\mathrm{CH} 149$, (k) $\mathrm{CH} 171$, (l) $\mathrm{CH} 172$, (m) $\mathrm{CH} 182$, (n) $\mathrm{CH} 186$, (o) $\mathrm{CH} 212$, (p) $\mathrm{CH} 362$.

association possibility, we validated some of candidate genes by quantitative real-time PCR ( $q$ PCR) (Additional file 5: Table S1, Additional file 6: Table S2) and their expression profiles in public databases.

$R$ genes play vital part in the detection of invading pathogens, and in the activation of defense mechanisms [30], among which NBS-LRR-type $R$ genes have been the most extensively studied research targets in plant genetics. The strongest association result (peak SNP: Chr11_6526998;
$P=1.17 \times 10^{-17}$ ), explaining up to $26.6 \%$ of the phenotypic variance, was around the gene Os11g0225100 (Figure 2a), which is one of the rice Pia-blast resistance gene and encodes NBS-LRR type protein from a region on chromosome 11 [27]. The expression of Os11g0225100 (Figure 2b) in the resistant landrace was higher than that in the susceptible landrace. After inoculation, the resistance level in the resistant landrace increased, while it has no change in the susceptible landrace. The expression profiles

Table 1 Genome-wide significant association signals of rice blast resistance using the EMMAX algorithm

\begin{tabular}{|c|c|c|c|c|c|c|}
\hline Strain & Chromosome & Position & Allele & $\mathrm{MAF}^{\mathrm{a}}$ & $P$-value & Known loci \\
\hline $\mathrm{CH} 102$ & 1 & 5686415 & $\mathrm{~T}, \mathrm{~A}$ & 0.068 & $6.14 \mathrm{E}-09$ & \\
\hline $\mathrm{CH} 102$ & 8 & 3774060 & $C, T$ & 0.063 & 4.36E-10 & \\
\hline $\mathrm{CH} 102$ & 9 & 10663921 & $\mathrm{G}, \mathrm{A}$ & 0.053 & 1.65E-09 & \\
\hline $\mathrm{CH} 102$ & 11 & 21585376 & $\mathrm{G}, \mathrm{A}$ & 0.057 & 2.97E-09 & \\
\hline $\mathrm{CH} 149$ & 2 & 24129162 & $C, T$ & 0.060 & $1.04 \mathrm{E}-09$ & \\
\hline $\mathrm{CH} 149$ & 4 & 1193240 & $C, T$ & 0.120 & $1.51 \mathrm{E}-09$ & \\
\hline $\mathrm{CH} 149$ & 4 & 24398518 & $A, C$ & 0.065 & 5.06E-09 & \\
\hline $\mathrm{CH} 149$ & 9 & 12562701 & $C, T$ & 0.078 & 1.30E-10 & \\
\hline $\mathrm{CH} 149$ & 11 & 30618466 & $\mathrm{G}, \mathrm{A}$ & 0.102 & 9.94E-09 & Pif [29] \\
\hline $\mathrm{CH} 149$ & 12 & 13690289 & $C, A$ & 0.060 & 7.53E-15 & \\
\hline $\mathrm{CH} 171$ & 4 & 3571241 & $\mathrm{G}, \mathrm{A}$ & 0.068 & $6.28 \mathrm{E}-11$ & \\
\hline $\mathrm{CH} 171$ & 5 & 22378428 & $A, T$ & 0.063 & 3.27E-10 & \\
\hline $\mathrm{CH} 171$ & 6 & 22777049 & $C, T$ & 0.057 & 2.05E-09 & \\
\hline $\mathrm{CH} 171$ & 7 & 1181446 & $A, G$ & 0.052 & 2.95E-11 & \\
\hline $\mathrm{CH} 171$ & 11 & 16829017 & $A, G$ & 0.122 & 8.00E-09 & \\
\hline $\mathrm{CH} 171$ & 11 & 25107794 & $\mathrm{~T}, \mathrm{~A}$ & 0.065 & 3.09E-10 & \\
\hline $\mathrm{CH} 171$ & 12 & 18051954 & $C, T$ & 0.058 & 2.46E-09 & \\
\hline $\mathrm{CH} 171$ & 12 & 23040661 & $\mathrm{G}, \mathrm{A}$ & 0.089 & 2.33E-09 & \\
\hline $\mathrm{CH} 172$ & 12 & 10833734 & $C, A$ & 0.469 & 5.33E-10 & \\
\hline $\mathrm{CH} 172$ & 12 & 12959480 & $\mathrm{G}, \mathrm{A}$ & 0.467 & 1.98E-09 & \\
\hline $\mathrm{CH} 182$ & 3 & 1170958 & $A, G$ & 0.060 & 7.92E-09 & \\
\hline $\mathrm{CH} 182$ & 7 & 19794146 & $\mathrm{~T}, \mathrm{~A}$ & 0.070 & 1.16E-09 & \\
\hline $\mathrm{CH} 182$ & 8 & 5587272 & $C, T$ & 0.055 & 3.77E-09 & \\
\hline $\mathrm{CH} 182$ & 8 & 25225491 & $C, T$ & 0.055 & 3.87E-09 & \\
\hline $\mathrm{CH} 182$ & 11 & 27068156 & $C, T$ & 0.300 & 5.36E-09 & Pik [28] \\
\hline $\mathrm{CH} 182$ & 11 & 30606558 & $C, T$ & 0.060 & $2.94 \mathrm{E}-11$ & Pif [29] \\
\hline $\mathrm{CH} 182$ & 12 & 17934412 & $A, G$ & 0.076 & 2.85E-09 & \\
\hline $\mathrm{CH} 186$ & 12 & 13032951 & $\mathrm{G}, \mathrm{A}$ & 0.433 & 4.25E-13 & \\
\hline $\mathrm{CH} 212$ & 7 & 1616159 & $C, T$ & 0.172 & 2.40E-09 & \\
\hline $\mathrm{CH} 362$ & 11 & 6526998 & $\mathrm{G}, \mathrm{A}$ & 0.240 & $1.72 \mathrm{E}-17$ & Pia [27] \\
\hline
\end{tabular}

${ }^{a}$ MAF: minor allele frequency. 


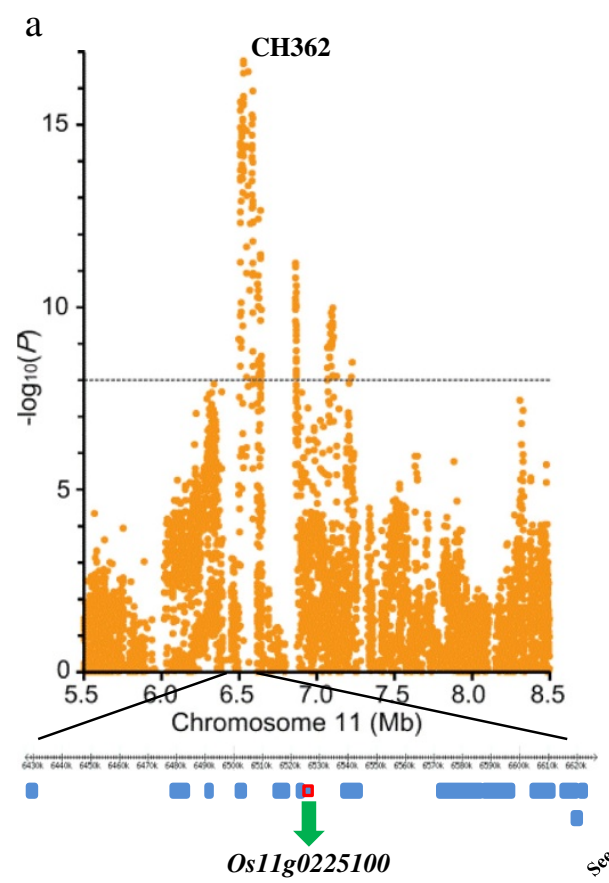

$\mathrm{b}$

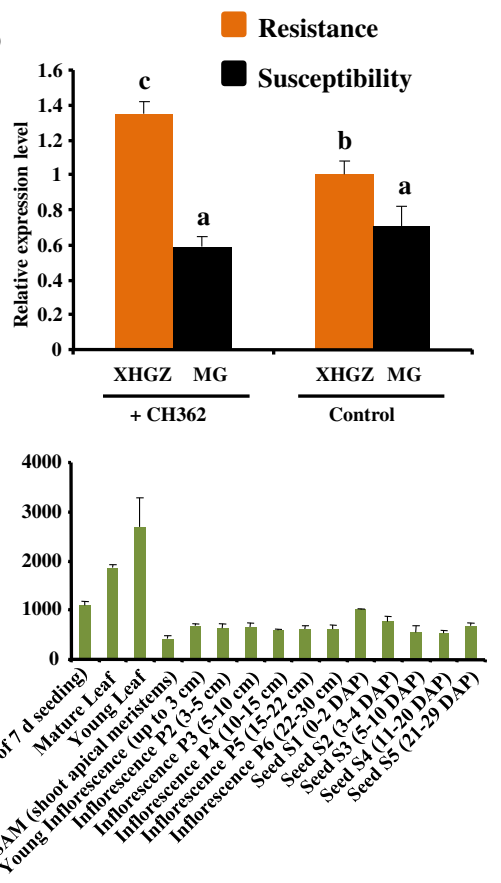

Figure 2 Associations and genomic locations of known gene, Os11g0225100. (a) The strongest signal located in the coding region. (b) Comparisons of expression before and after inoculation. (c) The expression pattern of Os 11 g0225100 from public microarray data.

from microarray data (Figure 2c) indicated that the Os11g0225100 gene has a high expression level in young leaf, mature leaf and seeding root.

We observed additional signals located $\pm 13 \mathrm{~kb}$ and $0.5 \mathrm{~kb}$ downstream of the Pif, a rice blast disease QTL identified by a previous study [29] and mapped on chromosome 11. These SNPs were associated with CH182 (Chr11_30606558, $P=2.94 \times 10^{-11}$, Figure 3a) and CH149 (Chr11_30618466, $P=9.94 \times 10^{-9}$, Figure $3 \mathrm{~b}$ ), respectively explaining $13.6 \%$ and $15.9 \%$ of the phenotypic variance. Os11g0704100 is described as a disease resistance protein containing nucleotide-binding and leucine-rich repeat (NB-LRR) domain, suggesting that Os11g0704100 is the largest extent candidate gene for Pif. As shown in $q$ PCR (Figure 3c,d), the expression of Os11g0704100 was similar to that of Os11g0225100. The expression profiles from microarray data (Figure $3 \mathrm{e}$ ) showed that the gene was constitutively expressed at a low level. Thus, we speculated that the disease resistance protein Os11g0704100 might be the large extent candidate gene for Pif.

Members of the kinase protein family also participate in $R$ gene-mediated disease resistance, such as the reported genes Pto (in tomato) [31], Xa21 (in rice) [32], and Rpg1 (in barley) [33]. A significant SNP (Chr12_13690289, $P=7.53 \times 10^{-15}$, Figure 4a) associated with $\mathrm{CH} 149$ for a cluster of six genes (Table 2), explaining $18.0 \%$ of the phenotypic variance. According to gene ontology (GO) analysis, Os12g0424700 and Os12g0427000 were described as kinase-like domain containing protein and identified as the priori candidate genes underlying this locus. For Os12g0424700, the result of $q$ PCR (Figure 4b) was also similar to Os11g0225100. And the expression profiles from microarray data (Figure 4d) indicated that Os12g0424700 has a low expression level, with a peak during inflorescence P6 $(22-30 \mathrm{~cm})$. For Os12g0427000, the expression level decreased after inoculation (Figure 4c) and it has a low expression level in most tissues and organs (Figure 4e), similar to Os11g0704100. Therefore, we speculated that the two genes might be required for the full function of this locus. This is similar to the situations in rice Pikm [34], Pi5 [35], and Arabidopsis RRS1 and RPS4 [36], which demonstrated that the exact same phenotype of complete disease resistance can be the result of different loci.

To evaluate whether novel functional loci were implicated by GWAS, we further explore significant SNP, Chr12 $13032951\left(P=4.25 \times 10^{-13}\right)$, on chromosome 12 . This SNP was significantly associated with the strain $\mathrm{CH} 186$ (Figure 5a), and explained up to $21.6 \%$ of the phenotypic variance. Searching the flanking region, ten candidate genes were involved, referring to zinc finger protein, histone $\mathrm{H} 3$, putative plant transposon protein and so on (Table 3). Our qPCR analysis (Figure 5b,c, Additional file 7: Figure S5) demonstrated that Os12g0416300, Os12g0417100, and Os12g0417600 might be the most promising candidate genes participated positive regulations for this region. Os12g0416300 (Figure 5b) and Os12g0417600 (Figure 5d) had a higher expression levels in the resistant landraces compared with those in the susceptible landraces, and no 

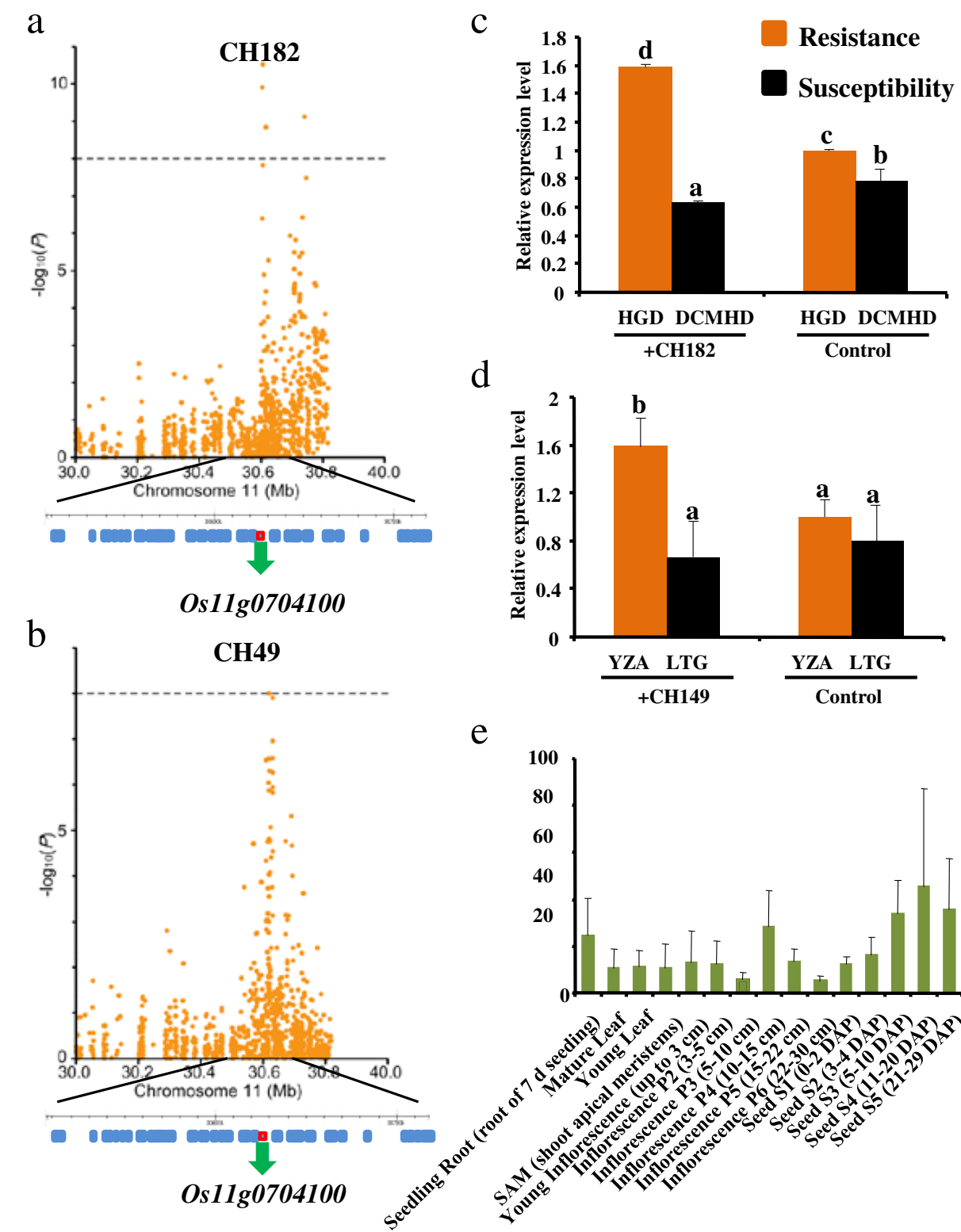

d

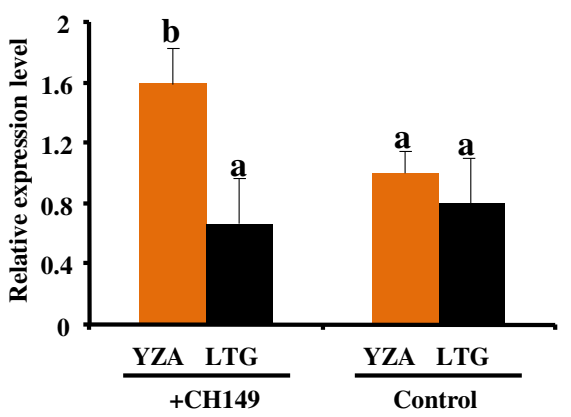

e
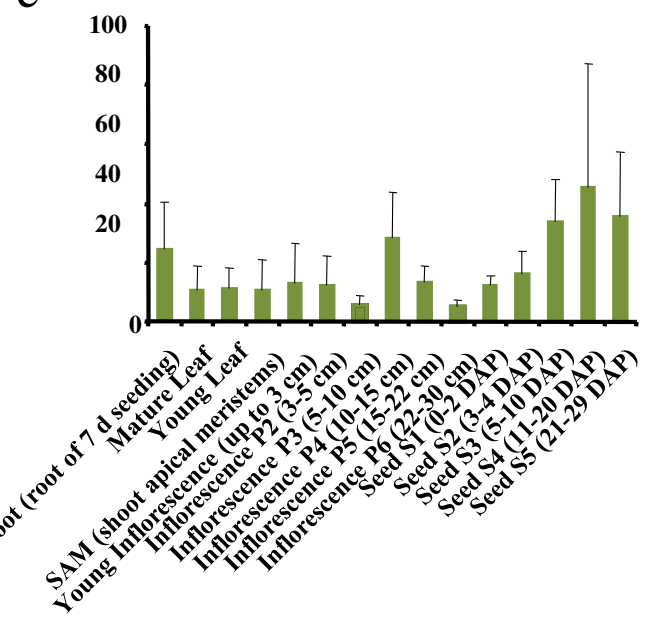

Figure 3 The strong associated signal near previously identified QTL, Pif. (a) Association with CH182. (b) Association with CH149. Comparisons of expression before and after inoculation. (c) Inoculation with the strain, $\mathrm{CH} 182$. (d) Inoculation with the strain, $\mathrm{CH} 149$. (e) The expression pattern of Os11g0704100 from public microarray data.

difference between before and after inoculation. Unlike them, the expression level of Os12g0417100 (Figure 5c) increased after inoculation. In addition, the microarray data showed that Os12g0417100 (Figure 5e) were constitutively expressed at a low level, Os12g0417600 (Figure 5f) had a high expression level during the inflorescence P6 $(22-30 \mathrm{~cm})$ and weak expression levels in other tissues and organs at various development stages. There were no probes in the microarray for Os12g0416300. For others, they might be no role in the regulation of blast resistance or as negative regulation (Additional file 8: Figure S6).
Of the other SNPs reaching genome-wide significance, Chr11_27068156 $\left(P=5.36 \times 10^{-9}\right)$ was $\pm 37 \mathrm{~kb}$ upstream of the known cloned gene, $P i k$, which is also composed of two adjacent NBS-LRR genes and confers high and stable resistance to many Chinese rice blast isolates [28]. More interesting, we discovered a signal (Chr03_1170958, $P=7.92 \times 10^{-9}$, Figure 1e, m) associated on Chromosome 3 , where there is no relative blast resistance loci reported. Searching the flanking region (Additional file 9: Table S3), Os03g0122000 encodes kinase-like domain containing protein, and Os03g0120400 encodes heavy metal transport/ 


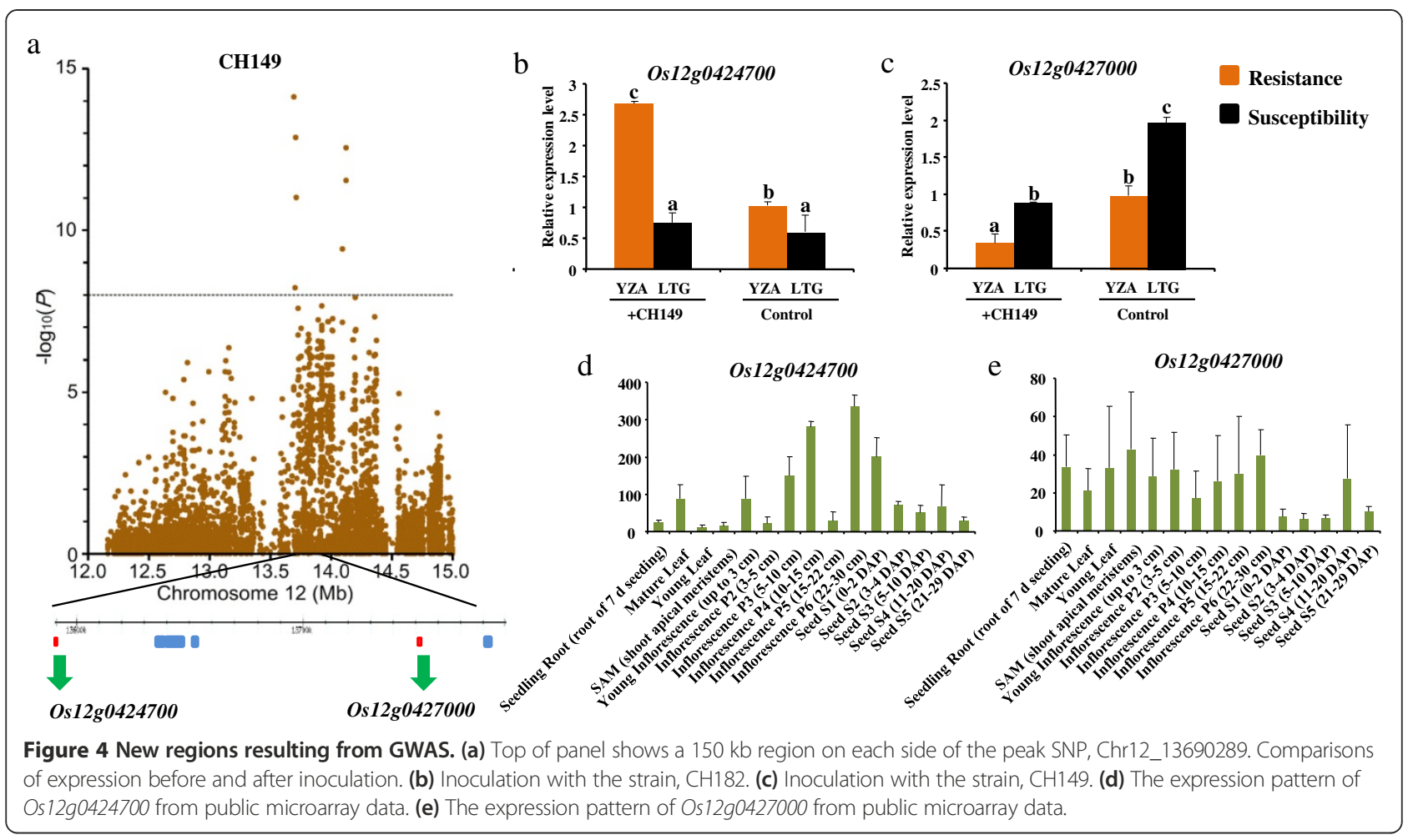

detoxification protein domain containing protein, and so on. Though it is unclear what gene participate the resistance regulation, the region would be further investigated.

\section{Discussion}

In this work, GWAS was used for association mapping of quantitative disease resistance genes to rice blast disease, which is similar to work performed in maize [37]. The use of high-density genome-wide SNPs in GWAS not only allows the discovery of true candidate genes, but also enables a comprehensive view of the regulatory mechanism of the traits.

Although genome-wide association studies are becoming more and more feasible, it seems likely that population structure will still be subject to considerable debate, which may result in an increase rate of the false-positives [38].

\section{Table 2 Summary of six candidate genes for}

Chr12_13690289

\begin{tabular}{ll}
\hline Candidate gene & Annotation description \\
\hline Os12g0424700 & Protein kinase-like domain containing protein. \\
Os12g0425500 & $\begin{array}{l}\text { Non-protein coding transcript/uncharacterized } \\
\text { transcript }\end{array}$ \\
Os12g0425600 & Growth regulator related protein \\
Os12g0425800 & Hypothetical protein \\
Os12g0427000 & Protein kinase-like domain containing protein \\
Os12g0427600 & Proteinase inhibitor 19 subtilisin propeptide \\
& domain containing protein \\
\hline
\end{tabular}

However, the extent of the problem not only depends on the extent to that the sample is structured, but also on the phenotype [39]. A trait that is strongly affected by population structure will display a higher false-positive rate [40-42]. In order to be less prone to false-positives resulted from genetic structure, our study only used the indica panel and optimized all of the parameters in the EMMAX algorithm. In fact, although the EMMAX algorithm, or mixed line model [43], reduced the inflation of the $P$-value, it could often mask the true loci and decrease the detection power [12]. In this context, most association mapping of human studies are likely to be casecontrol studies, given a judiciously chosen control [44].

Despite these limitations, we identified 30 loci associated with rice blast disease resistance in the indica panel, with one located on chromosome 3 . It is no doubt that there is pseudo information in the data, and not practical to thoroughly predict the false association from true. To analyze the candidate genes, we combined gene annotation, $q \mathrm{PCR}$ and expression profile from microarray data to investigate the potential functional polymorphisms capable of causing changes in the phenotype. Of these associated loci, some were overlapped or coincided with previously identified genes and QTLs [27-29]. If the range was extended to $300 \mathrm{~kb}( \pm 150 \mathrm{~kb})$, more known genes might have been detected, such as Pita $[7,45,46]$. In addition, we detected newly associated loci that were characterized by the presence of $R$ genes. Furthermore, it is worth noting that the strongest association did not always correspond to the 


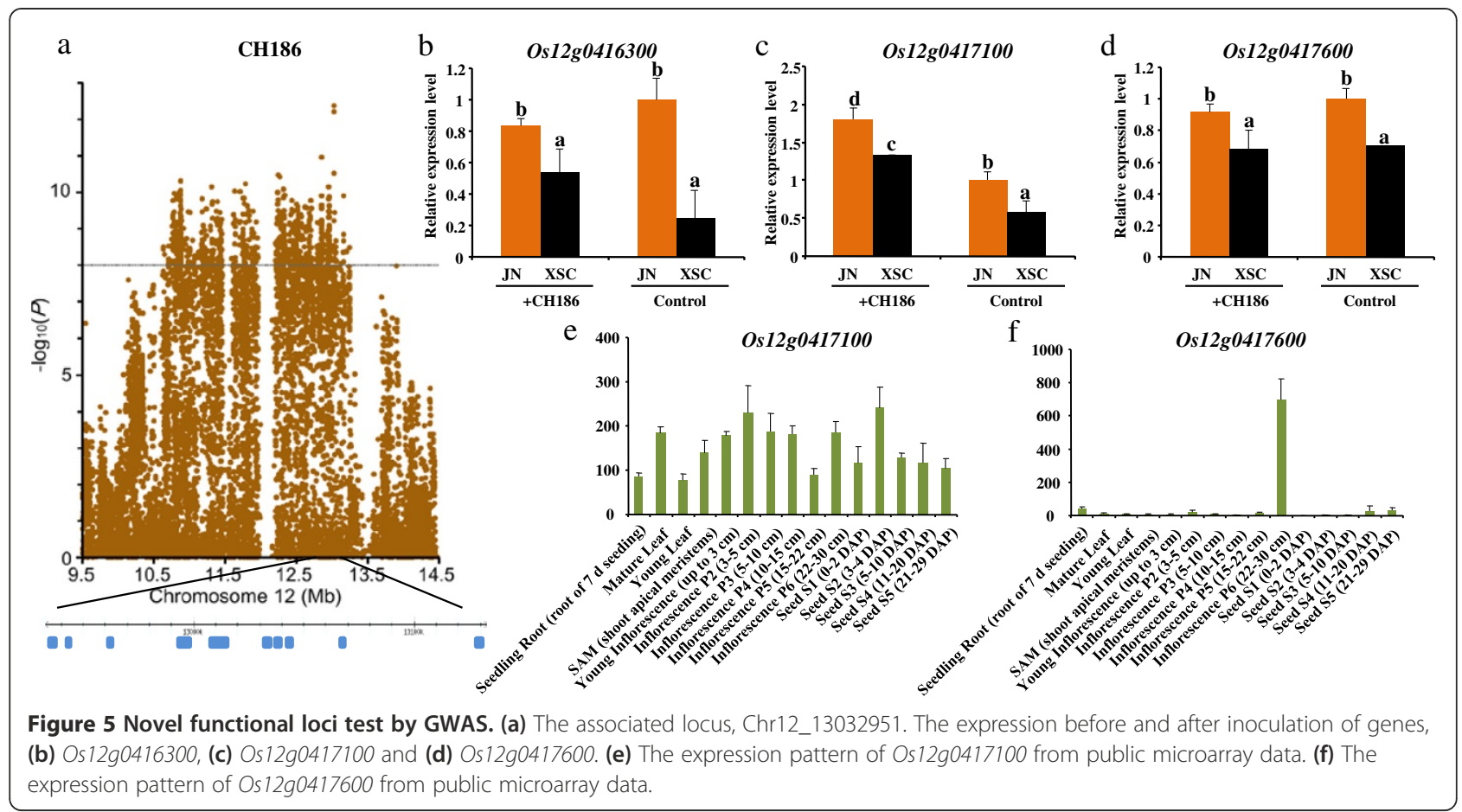

candidate genes, which might reflect an ascertainment bias [12], and these genes may be more interesting because of their participation in metabolic regulation [38]. The results demonstrated that rice blast disease resistance was conditioned by a range of mechanisms [47], and that there is considerable mechanistic overlap with basal resistance [48].

Chromosomal hotspots are frequently found for rice blast disease, and chromosome 11, as previously reported, had the most associated loci: 15 loci referring to 24 major blast resistance genes (http://www.ricedata.cn/gene). In this study, associated loci and candidate genes were also frequently found on chromosome 11. Yu et al. [49] discovered that the highest frequency of copy number variations (CNVs) for rice was on chromosome 11, and genes in many $\mathrm{CNVs}$ were involved in resistance. Most of these encode proteins with conserved nucleotide-binding sites (NBS) and leucine-rich repeats (LRRs). Meanwhile, NBS-LRR genes in plants are inclined to cluster at the adjacent loci within genomes [50]. We also analyzed a cluster of candidate genes that cooperatively participated in functional regulation of blast disease resistance, or had a direct role in regulation, as observed in the a previous study [28]. The explanation to the hotspots might be the occurrence of biochemical connections or that they are highly related with the original rice genome, pointing to the same genomic position.

We found that several SNPs were associated with the same strain. And this might be multigenic effect and attributed to the accumulation of numerous loci, influenced by epistatic effect and additive effect. In addition, some

Table 3 Summary of ten candidate genes for Chr12_13032951

\begin{tabular}{|c|c|c|c|}
\hline Strain & Associated loci & Candidate gene & Description \\
\hline $\mathrm{CH} 186$ & Chr12_13032951 & Os12g0414900 & Zinc finger RanBP2-type domain containing protein \\
\hline $\mathrm{CH} 186$ & Chr12_13032951 & Os12g0415400 & Similar to Histone $\mathrm{H} 3$ \\
\hline $\mathrm{CH} 186$ & Chr12_13032951 & Os12g0415800 & Similar to Histone $\mathrm{H} 3$ \\
\hline $\mathrm{CH} 186$ & Chr12_13032951 & Os12g0416300 & Conserved hypothetical protein \\
\hline $\mathrm{CH} 186$ & Chr12_13032951 & Os12g0416500 & GCN5-like 1 family protein \\
\hline $\mathrm{CH} 186$ & Chr12_13032951 & Os12g0416800 & Hypothetical protein \\
\hline $\mathrm{CH} 186$ & Chr12_13032951 & Os12g0416900 & Conserved hypothetical protein \\
\hline $\mathrm{CH} 186$ & Chr12_13032951 & Os12g0417000 & Putative plant transposon protein family protein \\
\hline $\mathrm{CH} 186$ & Chr12_13032951 & Os12g0417100 & Non-protein coding transcript unclassifiable transcript \\
\hline $\mathrm{CH} 186$ & Chr12_13032951 & Os12g0417600 & Non-protein coding transcript putative npRNA \\
\hline
\end{tabular}


strains showed a significant association in the same region, indicating that these strains had similar genetic control, moreover, illustrating that these strains might have common mechanism and be caused by pleiotropic or closely linked genes [51]. This result was in line with classification according to the phenotype data. These correlations indicated that the mutation in this identified region was an important control point for blast disease and should be considered as a quantitative partial resistant to blast because of its generally non-race specificity. Otherwise, the different $P$ values of these correlations demonstrated that the loci may reflect unequal disease resistance for the various strains.

\section{Conclusions}

The use of high-density genome-wide SNPs in GWAS not only allows the discovery of true candidate genes, but also enables a comprehensive understanding of the regulatory mechanism of the traits. Our results further confirmed that GWAS is a powerful complementary approach for dissecting the quantitative disease resistant genes to traditional QTL mapping. This work provides the basis of further study of the potential function of these candidate genes. A subset of true associations would be weakly associated with outcome in any given GWAS; therefore, large-scale replication is necessary to confirm our results. Future research will focus on validating the effects of these candidate genes and their functional variants using genetic transformation and transferred DNA insertion mutant screens, to verify that these genes engender resistance to blast disease in rice.

\section{Methods}

\section{Plant materials}

The association mapping panel we used was composed of 517 Chinese rice landraces previously described in detail by Huang et al. [22] and deposited in the EBI European Nucleotide Archive(Accession numbers ERP000106), which included the indica panel (366 indica varieties) and the japonica panel (136 japonica varieties). Given the strong population differentiation between the two subspecies of cultivated rice, we did not look for associations across the entire set. Meanwhile, due to the less sample size of the japonica panel, we carried out GWAS for the subset of indica rice.

\section{Phenotypic variation}

Phenotypic measurements were obtained at the China National Rice Research Institute Farm in Hangzhou, China at $\mathrm{N} 30^{\circ} 32^{\prime}, \mathrm{E} 120^{\circ} 12^{\prime}$ in 2012 . Seeds were planted in plastic trays $(43 * 30 * 7.5 \mathrm{~cm})$ to test blast resistance for 16 strains (CH102, CH122, CH131, CH149, CH154, CH159, CH171, CH172, CH182, CH186, CH193, CH212, CH218, CH242, CH251, CH362) represent collected from all over China. Fifteen seeds were planted in each of six rows and ten ranks per tray with three replications. Plants were incubated at the third-to-fourth leaf stage by the spraying method in low light and at room temperature as well as high humidity (between 70 and 85\%) to ensure sporulation and subsequent reinfection of susceptible plants. The disease reactions were measured about 7 $\mathrm{d}$ after inoculation, and evaluated by diseased leaf area (DLA) [52]. Higher DLA among replications was used in the analysis.

\section{Genotyping and association mapping}

We used the sequencing data of Huang et al. [21,22] in the Rice Haplotype Map Project Database (http://www.ncgr.ac. $\mathrm{cn} /$ RiceHap2). SNPs with a minor allele frequency $>5 \%$ were used for the association analyses. We used the Efficient Mixed-Model Association eXpedited (EMMAX) algorithm to carry out the GWAS [25].

\section{Analysis of significant signals}

To identify candidate genes and predict their putative functions in the associated loci for the corresponding strain, we used gene annotation information from the Rice Annotation Project Database (RAP-DB). All potential candidate genes in the associated loci, which had specific roles in rice blast resistance responses, were selected within a 200-kb genome region (100 kb upstream and $100 \mathrm{~kb}$ downstream of the peak SNPs).

\section{Identification of the candidate genes}

The expression levels of the candidate genes before and after blast disease infection were measured using quantitative real-time PCR ( $q$ PCR). Total RNA was extracted from young rice leaves using an AxyPrep ${ }^{\mathrm{TM}}$ Multisource Total RNA Miniprep Kit from Axygen (Tewksbury, MA, USA). Complementary DNA (cDNA) was synthesized with a dT18 primer from total RNA using the First Strand cDNA Synthesis Kit from Toyobo Co. (Osaka, Japan). Quantitative real-time PCR ( $q$ PCR) primers (Additional file 5: Table S1) and materials (Additional file 6: Table S2) for amplification were designed, and the reaction was performed on a 7500 Real-Time PCR system (Applied Biosystems, Carlsbad, CA, USA). The expression level of $\beta$-actin was used to standardize the RNA sample for each analysis. The $q \mathrm{PCR}$ assay was performed at least three times for each experimental line. The expression profile analyses were also performed using the database in the BioArray Resource for Plant Biology (http://bar.utoronto.ca).

\section{Additional files}

Additional file 1: Figure S1. Geographical distribution of phenotypic variation for 16 strains. Red dots indicate resistance; green dots indicate moderate susceptibility; black dots indicate susceptibility. 
Additional file 2: Figure S2. UPGMA dendrogram of 16 strains based on the SharedAllele distance.

Additional file 3: Figure S3. The number of the associated loci by GWAS in each chromosome.

Additional file 4: Figure S4. Functional category annotation for the associated loci by GWAS

Additional file 5: Table S1. Primers used for quantitative real-time PCR. Additional file 6: Table S2. Materials used for quantitative real-time PCR. Additional file 7: Figure S5. Quantitative real-time PCR analysis of the candidate genes for the associated locus, Chr12_13032951.

Additional file 8: Figure S6. Expression pattern analysis of the candidate genes for the associated locus, Chr12_13032951.

Additional file 9: Table S3. Summary of 20 candidate genes for Chr03_1170958.

\section{Competing interests}

The authors declare that they have no competing interests.

\section{Authors' contributions}

Conceived and designed the experiments: CW and XW. Performed the experiments: CW XY QX. Analyzed the data: CW YY XW. Contributed reagents/materials/analysis tools: XY YF HY YW. Wrote the paper: CW YY XW. All authors read and approved the final manuscript.

\section{Acknowledgments}

We thank to Dr. Yan Zhao and Dr. Xuehui Huang (Shanghai Institutes for Biological Sciences, Chinese Academy of Sciences) for technical support, to Dr. Xuehui Huang and Dr. Bin Han (National Center for Gene Research, Chinese Academy of Sciences) for their excellent discussions, constructive suggestion and critical reading of the manuscript. This work was supported by the Ministry of Science and Technology of China (2013CBA01404 and 2013BAD01B02-14) and the Ministry of Agriculture of China (2014NWB031).

\section{Author details}

'State Key Laboratory of Rice Biology, China National Rice Research Institute, Hangzhou 310006, China. ${ }^{2}$ College of Agricultural Sciences, Jiangxi Agricultural University, Nanchang 330045, China.

\section{Received: 16 July 2014 Accepted: 27 October 2014}

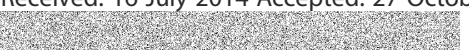

\section{References}

1. Zeigler RS, Leong SA, Teng P: Rice blast disease: Int Rice Res Inst; 1994

2. Barr ME: Magnaporthe, Telimenella, and Hyponectria (Physosporellaceae). Mycologia 1977, 69(5):952-966.

3. Dean RA, Talbot NJ, Ebbole DJ, Farman ML, Mitchell TK, Orbach MJ, Thon M, Kulkarni $\mathrm{R}$, Xu J-R, Pan $\mathrm{H}$, Read ND, Lee YH, Carbone I, Brown D, Oh YY Donofrio N, Jeong JS, Soanes DM, Djonovic S, Kolomiets E, Rehmeyer C, Li W, Harding M, Kim S, Lebrun MH, Bohnert H, Coughlan S, Butler J, Calvo S, $\mathrm{Ma} L-J$, et al: The genome sequence of the rice blast fungus magnaporthe grisea. Nature 2005, 434(7036):980-986

4. Liu J, Liu X, Dai L, Wang G: Recent progress in elucidating the structure, function and evolution of disease resistance genes in plants. J Genet Genomics 2007, 34(9):765-776.

5. Wang G-L, Mackill DJ, Bonman JM, McCouch SR, Champoux MC, Nelson RJ: RFLP mapping of genes conferring complete and partial resistance to blast in a durably resistant rice cultivar. Genetics 1994, 136(4):1421-1434.

6. Wang ZX, Yano M, Yamanouchi U, Iwamoto M, Monna L, Hayasaka H, Katayose $Y$, Sasaki T: The Pib gene for rice blast resistance belongs to the nucleotide binding and leucine-rich repeat class of plant disease resistance genes. Plant J 1999, 19(1):55-64.

7. Bryan GT, Wu K-S, Farrall L, Jia Y, Hershey HP, McAdams SA, Faulk KN, Donaldson GK, Tarchini R, Valent B: A single amino acid difference distinguishes resistant and susceptible alleles of the rice blast resistance gene Pi-ta. Plant Cell Online 2000, 12(11):2033-2045.

8. Qu S, Liu G, Zhou B, Bellizzi M, Zeng L, Dai L, Han B, Wang G-L: The broadspectrum blast resistance gene Pi9 encodes a nucleotide-binding site- leucine-rich repeat protein and is a member of a multigene family in rice. Genetics 2006, 172(3):1901-1914.

9. Fukuoka S, Saka N, Koga H, Ono K, Shimizu T, Ebana K, Hayashi N, Takahashi A Hirochika H, Okuno K, Yano M: Loss of function of a proline-containing protein confers durable disease resistance in rice. Science 2009, 325(5943):998-1001.

10. Fukuoka S, Okuno K: QTL analysis and mapping of pi21, a recessive gene for field resistance to rice blast in Japanese upland rice. Theor App/ Genet 2001, 103(2-3):185-190.

11. Ellingboe A, Chao C-CT: Genetic interactions in magnaporthe grisea that affect cultivar specific avirulence/virulence on rice. In Rice Blast Disease Edited by Zeigler RS, Leong SA, TengP S. Wallingford: CAB International; 1994:51-64.

12. Zhao K, Tung C-W, Eizenga GC, Wright MH, Ali ML, Price AH, Norton GJ, Islam MR, Reynolds A, Mezey J: Genome-wide association mapping reveals a rich genetic architecture of complex traits in oryza sativa. Nat Commun 2011, 2:467.

13. C-q Z, Hu B, Zhu K-Z, Zhang H, Leng Y-I, Tang S-Z, Gu M-h, Liu Q-q: QTL mapping for rice RVA properties using high-throughput re-sequenced chromosome segment substitution lines. Rice Sci 2013, 20(6):407-414.

14. Edwards AO, Ritter R, Abel KJ, Manning A, Panhuysen C, Farrer LA: Complement factor $\mathrm{H}$ polymorphism and age-related macular degeneration. Science 2005, 308(5720):421-424.

15. Helgadottir A, Thorleifsson G, Manolescu A, Gretarsdottir S, Blondal T, Jonasdottir A, Jonasdottir A, Sigurdsson A, Baker A, Palsson A, Masson G, Gudbjartsson DF, Magnusson KP, Andersen K, Levey Al, Backman VM, Matthiasdottir S, Jonsdottir T, Palsson S, Einarsdottir H, Gunnarsdottir S Gylfason A, Vaccarino V, Hooper WC, Reilly MP, Granger CB, Austin H, Rader DJ, Shah SH, Quyyumi AA, et al: A common variant on chromosome 9p21 affects the risk of myocardial infarction. Science 2007, 316(5830):1491-1493.

16. Wang K, Diskin SJ, Zhang H, Attiyeh EF, Winter C, Hou C, Schnepp RW, Diamond M, Bosse K, Mayes PA, Glessner J, Kim C, Frackelton E, Garris M Wang Q, Glaberson W, Chiavacci R, Nguyen L, Jagannathan J, Saeki N, Sasaki H, Grant SFA, Iolascon A, Mosse YP, Cole KA, Li Z, Devoto M, McGrady PW, London WB, Capasso M, et al: Integrative genomics identifies LMO1 as a neuroblastoma oncogene. Nature 2010, 469(7329):216-220.

17. Xu J, Mo Z, Ye D, Wang M, Liu F, Jin G, Xu C, Wang X, Shao Q, Chen Z, Tao Z, Qi J, Zhou F, Wang Z, Fu Y, He D, Qiang W, Guo J, Wu D, Gao X, Yuan J, Wang G, Xu Y, Wang G, Yao H, Dong P, Jiao Y, Shen M, Yang J, Ou-Yang J, et al: Genome-wide association study in Chinese men identifies two new prostate cancer risk loci at 9q31. 2 and 19q13. 4. Nat Genet 2012, 44(11):1231-1237.

18. Jia G, Huang X, Zhi H, Zhao Y, Zhao Q, Li W, Chai Y, Yang L, Liu K, Lu H, Zhu C, Lu Q, Zhou C, Fan D, Weng Q, Guo Y, Huang T, Zhang L, Lu T, Feng Q, Hao H, Liu H, Lu P, Zhang N, Li Y, Guo E, Wang S, Wang S, Liu J, Zhang W, et al: A haplotype map of genomic variations and genome-wide association studies of agronomic traits in foxtail millet (Setaria italica). Nat Genet 2013, 45(8):957-961.

19. Goff SA, Ricke D, Lan T-H, Presting G, Wang R, Dunn M, Glazebrook J, Sessions A, Oeller P, Varma H, Hadley D, Hutchison D, Martin C, Katagiri F, Lange BM, Moughamer T, Xia Y, Budworth P, Zhong J, Miguel T, Paszkowski U, Zhang S, Colbert M, Sun W, Chen L, Cooper B, Park S, Wood TC, Mao L, Quail P, et al: A draft sequence of the rice genome (Oryza sativa L. ssp. japonica). Science 2002, 296(5565):92-100.

20. Yu J, Hu S, Wang J, Wong GK-S, Li S, Liu B, Deng Y, Dai L, Zhou Y, Zhang X, Cao M, Liu J, Sun J, Tang J, Chen Y, Huang X, Lin W, Ye C, Tong W, Cong L, Geng J, Han Y, Li L, Li W, Hu G, Huang X, Li W, Li J, Liu Z, Li L, et al: A draft sequence of the rice genome (Oryza sativa L. ssp. indica). Science 2002, 296(5565):79-92.

21. Huang X, Wei X, Sang T, Zhao Q, Feng Q, Zhao Y, Li C, Zhu C, Lu T, Zhang Z, Li M, Fan D, Guo Y, Wang A, Wang L, Deng L, Li W, Lu Y, Weng Q, Liu K, Huang T, Zhou T, Jing Y, Li W, Lin Z, Buckler E, Qian Q, Zhang Q, Li J, Han B: Genome-wide association studies of 14 agronomic traits in rice landraces. Nat Genet 2010, 42(11):961-967.

22. Huang X, Zhao Y, Wei X, Li C, Wang A, Zhao Q, Li W, Guo Y, Deng L, Zhu C, Fan D, Lu Y, Weng Q, Liu K, Zhou T, Jing Y, Si L, Dong G, Huang T, Lu T, Feng Q, Qian Q, Li J, Han B: Genome-wide association study of flowering time and grain yield traits in a worldwide collection of rice germplasm. Nat Genet 2012,44(1):32-39.

23. Chakraborty $R$, Jin $L: A$ unified approach to study hypervariable polymorphisms: statistical considerations of determining relatedness 
and population distances. In DNA Fingerprinting: State of the Science. Basel: Birkhäuser; 1993:153-175.

24. Sneath P, Sokal R: Numerical Taxonomy. San Francisco: W.H. Freeman and Company; 230-234.

25. Kang HM, Sul JH, Zaitlen NA, Kong S-y, Freimer NB, Sabatti C, Eskin E: Variance component model to account for sample structure in genome-wide association studies. Nat Genet 2010, 42(4):348-354.

26. Consortia Trcas: The sequence of rice chromosomes 11 and 12, rich in disease resistance genes and recent gene duplications. BMC Biol 2005, 3:20.

27. Okuyama Y, Kanzaki H, Abe A, Yoshida K, Tamiru M, Saitoh H, Fujibe T, Matsumura H, Shenton M, Galam DC, Undan J, Ito A, Sone T, Terauchi R: A multifaceted genomics approach allows the isolation of the rice Pia-blast resistance gene consisting of two adjacent NBS-LRR protein genes. Plant J 2011, 66(3):467-479.

28. Zhai C, Lin F, Dong Z, He X, Yuan B, Zeng X, Wang L, Pan Q: The isolation and characterization of Pik, a rice blast resistance gene which emerged after rice domestication. New Phytol 2011, 189(1):321-334.

29. Toriyama K: Breeding for resistance to major rice diseases in Japan. Los Banos, Philippines: Rice Breeding," International Rice Research Institute; 1972:253-281.

30. Jones JD, Dangl JL: The plant immune system. Nature 2006, 444(7117):323-329.

31. Bogdanove AJ, Martin GB: AvrPto-dependent Pto-interacting proteins and AvrPto-interacting proteins in tomato. Proc Natl Acad Sci 2000 97(16):8836-8840

32. Song W-Y, Wang G-L, Chen L-L, Kim H-S, Pi L-Y, Holsten T, Gardner J, Wang B, Zhai W-X, Zhu L-H, Fauquet C, Ronald P: A receptor kinase-like protein encoded by the rice disease resistance gene, Xa21. Science 1995, 270(5243):1804-1806

33. Brueggeman R, Rostoks N, Kudrna D, Kilian A, Han F, Chen J, Druka A, Steffenson B, Kleinhofs A: The barley stem rust-resistance gene Rpg1 is a novel disease-resistance gene with homology to receptor kinases. Proc Natl Acad Sci 2002, 99(14):9328-9333.

34. Ashikawa I, Hayashi N, Yamane H, Kanamori H, Wu J, Matsumoto T, Ono K, Yano M: Two adjacent nucleotide-binding site-leucine-rich repeat class genes are required to confer Pikm-specific rice blast resistance. Genetics 2008, 180(4):2267-2276.

35. Lee S-K, Song M-Y, Seo Y-S, Kim H-K, Ko S, Cao P-J, Suh J-P, Yi G, Roh J-H, Lee S, An G, Hahn TR, Wang G-L, Ronald P, Jeon J-S: Rice Pi5-mediated resistance to Magnaporthe oryzae requires the presence of two coiledcoil-nucleotide-binding-leucine-rich repeat genes. Genetics 2009, 181(4):1627-1638.

36. Narusaka M, Shirasu K, Noutoshi Y, Kubo Y, Shiraishi T, Iwabuchi M, Narusaka Y: RRS1 and RPS4 provide a dual Resistance-gene system against fungal and bacterial pathogens. Plant J 2009, 60(2):218-226.

37. Kump KL, Bradbury PJ, Wisser RJ, Buckler ES, Belcher AR, Oropeza-Rosas MA, Zwonitzer JC, Kresovich S, MCMullen MD, Ware D, Balint-Kurti P, Holland JB: Genome-wide association study of quantitative resistance to southern leaf blight in the maize nested association mapping population. Nat Genet 2011, 43(2):163-168.

38. Atwell S, Huang YS, Vilhjálmsson BJ, Willems G, Horton M, Li Y, Meng D, Platt A, Tarone AM, Hu TT, Jiang R, Muliyati NW, Zhang X, Amer MA, Baxter I, Brachi B, Chory J, Dean C, Debieu M, de Meaux J, Ecker JR, Faure N, Kniskern JM, Jones JDG, Michael T, Nemri A, RouX F, Salt DE, Tang C, Todesco M: Genomewide association study of 107 phenotypes in arabidopsis thaliana inbred lines. Nature 2010, 465(7298):627-631.

39. Aranzana MJ, Kim S, Zhao K, Bakker E, Horton M, Jakob K, Lister C, Molitor J, Shindo C, Tang C, Toomajian C, Traw B, Zheng H, Bergelson J, Dean C, Marjoram P, Nordborg M: Genome-wide association mapping in arabidopsis identifies previously known flowering time and pathogen resistance genes. PLoS Genet 2005, 1(5):e60

40. Stinchcombe JR, Caicedo AL, Hopkins R, Mays C, Boyd EW, Purugganan MD, Schmitt J: Vernalization sensitivity in Arabidopsis thaliana (Brassicaceae): the effects of latitude and FLC variation. Am J Bot 2005, 92(10):1701-1707.

41. Buckler ES, Holland JB, Bradbury PJ, Acharya CB, Brown PJ, Browne C, Ersoz E, Flint-Garcia S, Garcia A, Glaubitz JC, Goodman MM, Harjes C, Guill K, Kroon DE, Larsson S, Rosas MO, Rocheford TR, Romay MC, Romero S, Salvo S, Villeda HS, da Silva HS, Sun Q, Tian F, Upadyayula N, Ware D, Yates H, Yu J, Zhang Z Kresovich $S$, et al: The genetic architecture of maize flowering time. Science 2009, 325(5941):714-718.
42. Basanth Y, Sannaveerappanavar V, Gowda DS: Susceptibility of different populations of Nilaparvata lugens from major rice growing areas of Karnataka, India to different groups of insecticides. Rice Sci 2013, 20(5):371-378

43. Zhang Z, Ersoz E, Lai C-Q, Todhunter RJ, Tiwari HK, Gore MA, Bradbury PJ, Yu J, Arnett DK, Ordovas JM, Buckler E: Mixed linear model approach adapted for genome-wide association studies. Nat Genet 2010, 42(4):355-360.

44. Kettunen J, Tukiainen T, Sarin A-P, Ortega-Alonso A, Tikkanen E, Lyytikäinen L-P, Kangas AJ, Soininen P, Würtz P, Silander K, Dick DM, Rose RJ, Savolainen MJ, Viikari J, Kähönen M, Lehtimäki T, Pietiläinen KH, Inouye M, McCarthy MI, Jula A, Eriksson J, Raitakari OT, Salomaa V, Kaprio J, Järvelin MR, Peltonen L, Perola M, Freimer NB, Ala-Korpela M, Palotie A, et al: Genome-wide association study identifies multiple loci influencing human serum metabolite levels. Nat Genet 2012, 44(3):269-276.

45. Khang CH, Park SY, Lee YH, Valent B, Kang S: Genome organization and evolution of the AVR-Pita avirulence gene family in the magnaporthe grisea species complex. Mol Plant Microbe Interact 2008, 21(5):658-670.

46. Singh PK, Thakur S, Rathour R, Variar M, Prashanthi SK, Singh AK, Singh UD, Sharma V, Singh NK, Sharma TR: Transposon-based high sequence diversity in Avr-Pita alleles increases the potential for pathogenicity of Magnaporthe oryzae populations. Funct Integr Genomics 2014, 14(2):419-429.

47. Sesma A, Osbourn AE: The rice leaf blast pathogen undergoes developmental processes typical of root-infecting fungi. Nature 2004, 431(7008):582-586.

48. Poland JA, Bradbury PJ, Buckler ES, Nelson RJ: Genome-wide nested association mapping of quantitative resistance to northern leaf blight in maize. Proc Natl Acad Sci 2011, 108(17):6893-6898.

49. Yu P, Wang C, Xu Q, Feng Y, Yuan X, Yu H, Wang Y, Tang S, Wei X: Detection of copy number variations in rice using array-based comparative genomic hybridization. BMC Genomics 2011, 12(1):372.

50. McHale L, Tan X, Koehl P, Michelmore RW: Plant NBS-LRR proteins: adaptable guards. Genome Biol 2006, 7(4):212.

51. Bergelson J, Roux F: Identifying the genetic basis of complex traits in Arabidopsis thaliana. Nat Rev Genet 2010, 11:867-879.

52. Notteghem J: Cooperative experiment on horizontal resistance to rice blast. In Blast and Upland Rice: Report and Recommendations from the meeting for International Collaboration in Upland Rice Improvement Los Baños. Los Baños, Filipinas: International Rice Research Institute; 1981:43-51.

doi:10.1186/s12870-014-0311-6

Cite this article as: Wang et al:: Genome-wide association study of blast resistance in indica rice. BMC Plant Biology 2014 14:311.

\section{Submit your next manuscript to BioMed Central and take full advantage of:}

- Convenient online submission

- Thorough peer review

- No space constraints or color figure charges

- Immediate publication on acceptance

- Inclusion in PubMed, CAS, Scopus and Google Scholar

- Research which is freely available for redistribution 